\title{
Changes in psychosocial adjustment after renal transplantation
}

\author{
J M Reynolds, M E Garralda, R J Postlethwaite, D Goh
}

\begin{abstract}
The psychological aspects of transplantation were studied in 29 children and adolescents with functioning renal transplants. Most parents rated their child's physical health as considerably improved after transplantation. They also noted improvements in the child's behaviour and in the quality of family life. When compared with a sample of children being treated by hospital haemodialysis, children who had received transplants had more favourable parental views of behavioural and emotional adjustment, better parental psychiatric adjustment, and indications of superior child rated mood, self concept, and social functioning. Children who had received transplants did, however, show an increase in minor behavioural symptoms compared with healthy controls, and most parents required continuing psychological and social support as well as attention to physical aspects of the child's condition.
\end{abstract}

Kidney transplantation is associated with improved psychosocial behaviour in children, but there is a continuing need for support for parents in dealing with minor psychological problems after the transplant.

'Most, if not all, paediatric nephrologists caring for infants, children and adolescents with end stage renal disease would advocate successful renal transplantation as the optimal therapeutic modality. This bias is based upon the belief that rehabilitation is significantly superior following successful renal transplantation than that possible with any currently available dialysis modality and that the potential for growth and pubertal development is significantly increased following successful transplantation."

The success at achieving this ideal varies from region to region and from country to country. Detailed regional statistics are not available but there is information from different countries. In $1987,5 \cdot 1$ new patients under the age of 15 years per million child population were accepted into end stage renal failure programmes in the United Kingdom. ${ }^{2}$ The programme in the North West region of England accepted 8.2/ million child population. In 1986 half the children with end stage renal disease in Europe had functioning transplants compared with $60 \%$ in this unit. ${ }^{3}$ In addition to an overall rise in the number of children being treated the age range has also widened, with increasing numbers of infants and younger children now undergoing successful transplantation. These developments in treatment give rise to a need for a better understanding of the psychosocial changes experienced by this group of children and their parents.

Since the start of transplant programmes for children there have been a number of reports about the social adjustment of children after transplantation. Considerable improvements have been reported in children's health and social functioning after stormy phases immediately after the transplants, and it has been concluded that children with successful transplants have fewer psychosocial difficulties and are better rehabilitated to normal life than those treated by long term dialysis. ${ }^{4-6}$ There have, however, been no reports confirming improvements in adjustment by comparing children before and after transplantation. Moreover, in earlier studies children at different stages of treatment (on dialysis and after transplantation) were often studied as one group, thus obscuring differences in psychosocial functioning that could have been attributable to the different stages of treatment.

Some problems that occur after transplantation have been highlighted, including symptoms of depression, poor self esteem, noncompliance with treatment, and preoccupation and concern about the side effects of immunosuppressive medication and poor growth. ${ }^{78} \mathrm{~A}$ recent long term outcome study indicated considerable psychological problems, with a quarter of subjects having seen a doctor for a persistent emotional or psychiatric problem in early adulthood. ${ }^{9}$ Many authors have noted that ongoing support is necessary to minimise these adverse effects.

Workers in our department have investigated the psychological and social functioning of children at various stages of end stage renal disease and their families. ${ }^{10} 11$ Differences in psychosocial adjustment were identified that related to the stage and severity of illness, with a high incidence of difficulties in psychological adjustment among children on hospital haemodialysis, and of minor difficulties in adjustment in schools particularly among a group not yet receiving dialysis. These results highlight the importance of considering or sampling separately subjects at different stages in treatment. Many of the children in our previous study went on to have successful transplant operations. This gave us the opportunity to compare their psychosocial adjustment after transplantation with their adjustment before and during haemodialysis with comparable measures. We were also interested in identifying what psychosocial support, if any, was required by parents after trans-
Correspondence to: Mrs Reynolds.

Accepted 28 November 1990

University of
Manchester,
Booth Hall
Children's Hospital,
Charlestown Road,
Blackley,
Manchester M9 2AA
Department of
Psychiatry
J M Reynolds
M E Garralda
Department of
Paediatric Nephrology
R J Postlethwaite
D Goh
Correspondence to:
Mrs Reynolds.
Accepted 28 November 19.90


plantation in addition to the medical support that was available.

\section{Patients and methods}

At the time of the study (1988-9) 29 patients $(76 \%)$ in the North West regional paediatric end stage renal failure programme had functioning transplants. The rest were on various dialysis treatments, of whom half were awaiting their first renal transplant and half had returned to dialysis after an unsuccessful transplant.

\section{PATIENTS WHO HAD RECEIVED TRANSPLANTS $(\mathrm{N}=29)$}

Patients who had received transplants were selected in two stages; in the summer of 1988 parents of all 26 children with transplants that had been functioning between eight and 72 months (mean 31.5 months) who were attending the transplant clinic at Booth Hall Hospital were asked to complete a questionnaire specially designed for this study. This asked about changes in the child's physical and psychological health since the transplant, changes in family life, and about support currently available for the parents. Later in the year and early in 1989 the parents and teachers of the (by then) 29 eligible children were asked to complete questionnaires about the child's psychiatric adjustment. Parents of schoolchildren $(n=26)$ completed the Rutter A behavioural questionnaire, and teachers completed the Rutter scale B. These scales consist of a list of symptoms or items the relative incidence and severity of which during the previous year is rated on a three point scale. The total score is computed and scores of 13 or more (parental scale) and of 9 or more (teachers' scale) indicate that the child has psychological problems and a high risk of psychiatric disorder. ${ }^{12}$ Parents of preschool children $(n=2)$ completed the behaviour checklist, ${ }^{13}$ and the one school leaver completed the general health questionnaire, which is a measure of adult mental distress or minor psychiatric morbidity. ${ }^{14}$ We also asked the parents of each child to give an overall judgment about whether they thought the child had behavioural or emotional problems and to indicate the degree of these difficulties on a three point scale.

Children over 7 years old were asked to complete a questionnaire to assess their depressive symptoms (the Birleson depression inventory ${ }^{15}$ ) and a self esteem questionnaire (the Lipsitt self concept scale ${ }^{1718}$ ); we used cut off points of 13 and 30 , respectively. Children were also asked to give details about their social lives. Parents were asked whether they had consulted their general practitioners or taken drugs for 'their nerves' during the preceding two years. They also completed the general health questionnaire (GHQ 28).

PATIENTS TREATED BY HOSPITAL

HAEMODIALYSIS $(\mathrm{N}=22)$

This group comprised all children attending

Booth Hall Hospital between September 1983 and August 1985 for a minimum of six months regular haemodialysis. There were 22 children ( 16 boys and six girls) with an age range of 3-18 years, mean 13). Seven of the children went on to receive transplants and were included in both the previous group and this one.

\section{PATIENTS NOT BEING TREATED BY DIALYSIS \\ $(\mathrm{N}=22)$}

Twenty two children with chronic renal failure attending the paediatric clinic but not receiving dialysis were matched for age and sex with the group receiving haemodialysis. Four children went on to receive transplants and were included in both this group and the group that had received transplants.

\section{HEALTHY CONTROLS $(\mathrm{N}=31)$}

This group comprised children selected from ordinary schools and a general practice that were attended by patients being treated by hospital haemodialysis. There were 31 children (21 boys and 10 girls) with an age range of 2-18 years, mean 13). Although the subjects in the sample were not individually matched with those receiving dialysis, the three study groups were comparable for age and sex distribution. Full details about the last three groups have been published previously. ${ }^{11}$

Information was obtained from parents and children (except those who had received transplants) by interviews, and they and the schoolteachers completed questionnaires. For the present comparison, scores from Rutter A and B questionnaires and parental reports of child behaviour and emotional problems were used. Children's scores from the Birleson and Lipsitt questionnaires and information obtained at the interviews about their social life were compared, as were parental scores on the general health questionnaires and reports of parental problems with their mental health that were recorded at interview.

At the time of the assessment $19(66 \%)$ of the patients were attending the transplant clinic every two to four weeks, and all but two of the rest were attending every four to eight weeks. The clinic is staffed by doctors and nurses known to the children from previous stages in their treatment, with additional input from a social worker and dietitian. Attention during clinic visits is paid both to physical and psychosocial aspects of the child's care, and parental support is also offered.

To assess the significance of differences among groups, the $\chi^{2}$ or Fisher's exact test were used. Because we were primarily interested in comparing adjustment in the children in whom end stage renal disease was most severe, we computed statistics comparing the groups treated by transplant and haemodialysis. In the tables we also give, for reference, the corresponding figures for those not being dialysed and the healthy sample.

\section{Results}

Information was obtained from 25 out of 26 sets 
of parents in the first stage of the study, and in the second stage all 29 sets of parents and their children agreed to take part ( 23 boys and six girls, mean age 11.5 years, range 1-17). Two of the children were from one family. All but two of the patients had had experience of continuous ambulatory peritoneal dialysis or haemodialysis and four children had previously had transplants. The questionnaires were all completed at a relatively stable point in the children's condition, although six were receiving outpatient treatment for serious problems of graft rejection. Though they were still being maintained on increased doses of immunosuppressive drugs, the length of time that the grafts would survive in these patients was thought to be limited. The sample included some children with non-renal complications, including two with mental handicaps and one with rectal atresia who had a colostomy.

Parents were asked to rate the degree and direction of change in the child's health and behaviour, and in the quality of family life since transplantation. The figure shows that virtually all the parents (92\%) reported improvements in their child's physical health and most considered the improvements to be considerable. Fewer but still a substantial number of parents (84\%) reported changes in the child's behaviour in the time since the transplant. As many of the changes were mixed (both positive and negative) as for the better, but none was reported to be for the worse. A high percentage of parents (88\%) reported changes in the quality of family life since transplantation. Of these, almost three quarters reported some improvement and none reported change for the worse.

As well as changes in these areas, we were interested in the parents' perception of their child's state at the time of assessment. The actual changes in health were reflected in parents' views of the child's current physical

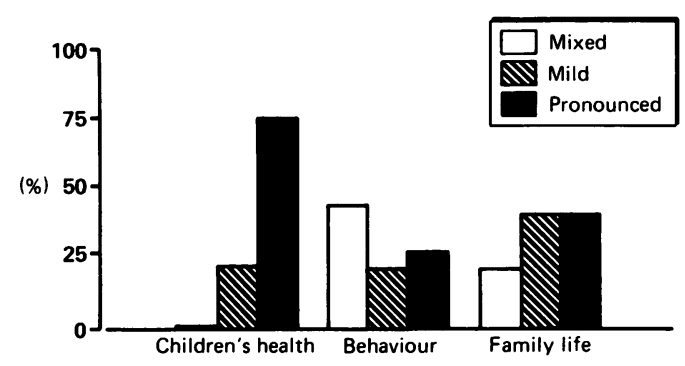

Percentage of parents reporting psychosocial improvements after transplantation $(n=25)$. No changes for the worse were reported, and not all parents noted changes. health, as only one third reported current problems, none of which was regarded as serious.

We asked parents to give their views about their child's behaviour and emotions at the time of assessment. Their comments were compared with those of parents of children not being treated with dialysis, undergoing hospital haemodialysis, and healthy controls (table 1). No parents in the transplant group felt that their children had serious difficulties. This compared favourably with both the other two groups of patients, in which more than one third of parents reported serious problems in behaviour. Children who had received transplants were often described at the time of assessment as 'normal in every way', or 'having only the ups and downs of a normal child'. The children were described as happier and less irritable than before transplantation; one young child was less aggressive and having fewer tantrums, and several adolescents were described as more confident and socialising better.

Reports were not universally positive, however, and 11 (39\%) of the children had minor behavioural difficulties, most related to issues associated with illness, such as fears of going into hospital or of medical proceduresparticularly the younger children. Unhappiness about appreance and poor growth were mentioned by parents of only two children as a cause of concern. Non-compliance with taking drugs was reported as a minor problem in two other children.

A similar number of parents $(n=10,38 \%)$ recorded behavioural problems on the parental Rutter A questionnaire. Seven children (70\%) with high scores were considered by their parents to be having minor behavioural difficulties. Behavioural problems in the Rutter A questionnaire were more than twice as common in the group who had had transplants than in either the group receiving haemodialysis or the healthy group. Scrutiny of the individual items scored by parents of transplant children, however, showed that the deviance was largely made up of a number of mild behaviour symptoms, with severe symptoms rarely being scored. The general health questionnaire score for the one school leaver was high and the behaviour checklist scores for the two preschool children did not indicate an excessive number of problems. Two children (7\%) were referred for psychiatric treatment.

The behaviour of the children with transplants at school, as assessed by the Rutter B questionnaire, did not differ appreciably from that of the healthy controls, but showed higher

Table 1 Child psychiatric adjustment

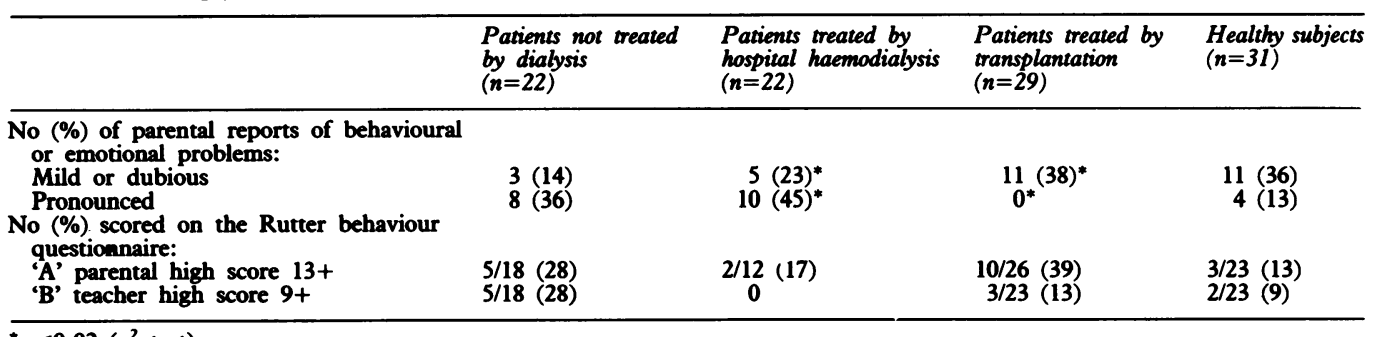

$* p<0.02\left(\chi^{2}\right.$ test $)$. 
scores than for children on haemodialysis. Not all children were capable of completing the questionnaires, and 25 completed questionnaires on mood changes, self concept, and social contacts. Table 2 shows that their ratings were generally comparable with those of healthy controls, but they reported less severe and more mild worrying than those not being treated with dialysis or those receiving haemodialysis. They also had lower depressive scores on the Birleson scale, fewer had self concept scores indicative of low self esteem, and more of them indicated a favourable social adjustment as shown by having a special friend.

Reports of problems with 'nerves' were recorded for all sets of parents but only one parent of each child completed the general health questionnaire. Table 3 shows that there were fewer longer term mental health problems among parents of children with transplants compared with parents of children on haemodialysis, the difference for mothers being significant $(p<0.05)$. There is a less striking difference, but none the less superior parental current mental state in the group whose children had received transplants, with rates similar to those of the parents of the healthy group.

At the time of assessment two thirds of parents whose children had received transplants reported no problems in family life. They reported far less disruption caused by the illness, with more freedom, more energy, and time for normal family activities such as going away on holiday. Many parents said that their lives had become happier and better organised, with freedom from dialysis and dietary restrictions and fewer visits to hospital. They reported that they felt less tired and isolated, having more time for their own lives, including work and social activities. Four parents also commented spontaneously on improvements in sibling behaviour and school progress. One third of parents, however, reported some problems in family life, including two who had a second child with chronic renal failure, one who had a child on continuous ambulatory peritoneal dialysis, and the mother of a patient with a transplant and non-renal complications. Others reported some continuing anxiety about their children's health and the future of the transplant, and one parent said that the family had been left physically and mentally drained since removal of the pressure of coping with ambulatory peritoneal dialysis.

There was a lower percentage of intact families among those who had received transplants (61\%) than among those receiving dialysis $(77 \%)$, those not being treated with dialysis $(91 \%)$, or healthy controls $(81 \%)$. This included a pronounced excess in the number of stepparents in the group who had received transplants; six $(21 \%)$ compared with none among those not being treated with dialysis or receiving haemodialysis, and two $(6 \%)$ in the healthy group. In all but two cases remarriage was not a consequence of but had preceded the transplant.

At follow up after transplant parents were asked about the areas in which they required and were offered support, and the degree of their satisfaction with this. All but one (96\%) noted that they received medical advice and information and $16(64 \%)$ reported receiving support directed towards their own worries about the child's condition. Help with broader psychosocial issues was also commonly reported, including concern about the child's behaviour or education $(n=16,64 \%)$, practical difficulties such as travelling expenses to hospi$\operatorname{tal}(n=15,60 \%)$ and with effects caused by the transplant on the family as a whole $(n=10$, $40 \%)$.

Parents sometimes commented spontaneously that although they had not needed or requested help, they thought it would have been available had they wanted it. Most $(n=15,60 \%)$ parents reported a lot of satisfaction with the amount of support and advice given at the clinic

Table 2 Child reports



${ }^{*} \mathbf{p}<0.02$ ( $\chi^{2}$ test).

Table 3 Parental mental health

\begin{tabular}{lllll}
\hline & $\begin{array}{l}\text { Patients not treated } \\
\text { by dialysis } \\
(n=20)\end{array}$ & $\begin{array}{l}\text { Patients treated by } \\
\text { hospital haemodialysis } \\
(n=20)\end{array}$ & $\begin{array}{l}\text { Patients treated by } \\
\text { transplantation } \\
(n=27)\end{array}$ & $\begin{array}{l}\text { Healthy subjects } \\
(n=31)\end{array}$ \\
\hline $\begin{array}{l}\text { No (\%) with mental health/nervous } \\
\text { problems during last two years: }\end{array}$ & $\begin{array}{c}11 / 20(55) \\
\text { Mothers }\end{array}$ & $\begin{array}{c}12 / 20(60)^{*} \\
3 / 19(16)\end{array}$ & $\begin{array}{l}7 / 27(26)^{*} \\
2 / 24(8)\end{array}$ & $\begin{array}{c}11 / 31(36) \\
1 / 26(4)\end{array}$ \\
$\begin{array}{l}\text { Fathers } \\
\text { No (\%) with current mental distress: } \\
\text { (general health questionnaire score 5+) } \\
\begin{array}{l}\text { Mothers } \\
\text { Fathers }\end{array}\end{array}$ & $\begin{array}{l}6 / 20(30) \\
2 / 9(22)\end{array}$ & $\begin{array}{l}6 / 15(40) \\
3 / 10(30)\end{array}$ & $6 / 23(26)$ & $8 / 29(28)$ \\
\hline * & & & & $2 / 11(18)$ \\
\hline
\end{tabular}


and four (16\%) said they were fairly satisfied. The remaining six $(24 \%)$ said they found the help offered satisfactory in some areas but not in others. Just under two thirds of parents said they did not need any more help from the hospital than that which had been offered, but nine (36\%) said they would have liked some more help in certain areas, such as further information about the long term or side effects of medication. Two mothers mentioned their own continuing worries about symptoms and fears of rejection, saying they were sometimes too reticent to ask all the questions they would have liked.

\section{Discussion}

Our findings show that the improved physical health of children after transplantation is paralleled by pronounced improvements in their parents' perceptions of the children's behaviour and emotions, and their own mental health, and in the children's perceptions of their mood, self esteem, and social life. Our findings also indicate that children and families function better after transplantation compared with those receiving hospital haemodialysis treatment. The findings are consistent with our previous reports in illustrating the importance of considering the stage of illness and treatment when investigating the pschosocial effects of chronic illness in children, as these may give rise to different rates and types of psychological morbidity. 1011

We considered the possibility that our positive findings reflected some bias in parental reporting. Parents are aware of how much is invested in a transplant by the medical team, and may in some way be responding to what they consider are the team's expectations. They did describe very graphically and convincingly, however, the improvements that had occurred both in the children and in the quality of family life. Moreover, this would not account for the better child rated self esteem and social life scores in patients with transplants than in those receiving haemodialysis.

Our results on the beneficial psychosocial effects of transplantation are in keeping with those of previous studies that used less systematic measures. ${ }^{4-619}$ Nevertheless, like previous authors of papers about social adjustment in children with transplants more than one year after transplantation, 8919 we found increased scores on the behavioural questionnaire in the group after transplant. This seems to contradict the parents' perceptions of the improved behaviour and emotional state in these children, but we think that it probably reflects the fact that the behavioural difficulties were mostly only minor. In most children therefore the high scores were due to cumulative mild ones, and few severe symptoms were present.

The finding of minor behaviour difficulties in children after transplants confirms our results that children with end stage renal failure that is not severe enough to require haemodialysis or transplantation have behaviour problems that are not severe, although they are seen predominantly at school. It seems plausible that children also have some problems after transplantation, reflecting their difficulties in making the transition from being ill to being healthy.

The rate of behavioural disturbance leading to psychiatric assessment was smaller than that in a follow up study into adulthood of subjects who had undergone transplantation in childhood, in which this was reported as $22 \%$ during the five years preceding the study. ${ }^{9}$ This could indicate either better general physical and psychological outcomes nowadays than when the transplants were carried out in the previous study, but it is also possible that the beneficial effects are not sustained. Longer follow up of our sample may reveal increased morbidity in early adulthood. The lower rate may, however, reflect the fact that there were close links between the paediatric and child psychiatry departments, which enabled regular discussions to take place between the psychiatrist and renal physicians. Problems about any patients were discussed as they arose in the multidisciplinary group and a plan for intervention agreed upon. This often obviated the need for formal psychiatric intervention.

Much has been made in previous reports of concerns by children about their appearance and it is surprising that such problems were not more widely reported in our study. ${ }^{89} 19$ Issues such as short stature, hirsutism, and body image emerge quite regularly as areas of concern, and it may be that interviews with the children themselves would have been necessary to assess fully the degree of these concerns. The children did report some worries, which were perhaps related to appearance and growth as well as to fears connected with admission to hospital (as reported by parents). For the most part, however, these worries did not seem to be handicapping. This does not detract from the need for attention to be given to subjects in whom specific concern is identified to reduce the likelihood of it affecting long term adjustment.

Our findings on child adjustment have to be viewed against the background of the improvements in the quality of family life and parental mental health, and the high levels of support offered and taken up by families at the transplant clinic. While there were some unmet needs, the degree of parental satisfaction was generally good. The support encompassed not just physical issues but also psychological and social ones and our results may not have been so favourable without it. The minor problems in psychological adjustment that the children still had could have escalated without appropriate support and guidance from staff at the clinics. A paediatric team that is aware of psychosocial issues will be able to meet many of the needs of transplant patients, but should be able to make specific referrals where appropriate.

Finally, there remains a number of children whose transplants fail, or for whom transplantation is not a possible option and other treatments such as continuous ambulatory peritoneal dialysis, or home or hospital haemodialysis, are required either permanently or as a stage in treatment. The differential effects of these treatments on social and psychological adjustment 
have not been investigated but are worth clarifying in view of our findings that it is possible to identify different psychosocial functioning among children at various stages of treatment.

We thank all the children and parents who took part in the study, the staff at Booth Hall Children's Hospital renal unit for their help, and the British Kidney Patients' Association, without whose help this work would not have been possible.

1 Fine RN, Tesani A. Renal transplantation in children. Nephron 1987;47:81-6.

2 Combined report on regular dialysis and transplantation of children in Europe in 1988. Nephrol Dial Transplant 1989;4 (suppl 4):31-40.

3 Combined report on regular dialysis and transplantation of children in Europe in 1987. Nephrol Dial Transplant 1988;3 (suppl):33-41.

4 Korsch BM, Fine RN, Grushkin CM, Negrete VF. ExperiKorsch BM, Fine RN, Grushkin CM, Negrete VF. Experi-
ences with children and their families during extended ences with children and their families during extended
hemodialysis and kidney transplantation. Pediatr Clin hemodialysis and kidney
North Am 1971;18:625-37.

5 Korsch BM, Negrete VF, Gardner JE, et al. Kidney transplantation in children: psychosocial follow up study on child and family. $\mathcal{F}$ Pediatr 1973;83:399-408.

6 Chantler C, Carter JE, Bewick M, et al. 10 Years' experience with regular haemodialysis and renal transplantation. Arch Dis Child 1980;55:435-45.

7 Bernstein DM. After transplantation-the child's emotional reactions. Am F Psychiatry 1971;127:1189-93.
8 Korsch BM, Fine RN, Negrete VF. Non-compliance in children with renal transplants. Pediatrics 1978;61:872-6. Henning P, Tomlinson L, Rigden SPA, Haycock GB, Chantler C. Long term outcome of treatment of end stage Chantler C. Long term outcome of treatment of
renal failure. Arch Dis Child 1988;63:35-40.

10 Garralda ME, Jameson RA, Reynolds JM, Postlethwaite RJ. Psychiatric adjustment in children with chronic renal failure. F Child Psychol Psychiatry 1988;29:79-90.

11 Reynolds JM, Garralda ME, Jameson RA, Postlethwaite RJ. How parents and families cope with chronic renal failure. Arch Dis Child 1988;63:821-6.

12 Rutter M, Tizard J, Whitmore K, eds. Education, health and behaviour. London: Longmans, 1970

13 Richman N, Stevenson J, Graham P. Pre-school to school: a behavioural study. London: Academic Press, 1982.

14 Goldberg D. Manual of the general health questionnaire. Windsor: NFER Publishing Company, 1978.

15 Birleson P. The validity of depressive disorder in childhood and the development of a self-rating scale: a research report. F Child Psychol Psychiatry 1981;22:73-89.

16 Birleson P, Hudson I, Buchanan DG, Wolff S. Clinical evaluation of a self-rating scale for depressive disorder in childhood (depression self-rating scale). $\mathcal{f}$ Child Psychol Psychiatry 1987;28:43-60.

17 Lipsitt LP. A self concept scale for children and its relation to the children's form of the manifest anxiety scale. Child Dev the children's form

18 Reese HW. Relationships between self-acceptance and sociometric choices. Fournal of Abnormal and Social Psychology 1961;62:472-4.

19 Klein SD, Simmons RG, Anderson CR. Chronic kidney disease and transplantation in childhood and adolescence. In: Blum RW, ed. Chronic illness and disabilities in childhood and adolescence. New York: Grune and Stratton, 1984: 429-557.

\section{Inhaled frusemide}

Inhaled frusemide reduces both the early and the late bronchoconstrictor responses of asthmatic subjects to antigen and protects against bronchoconstriction induced by exercise, nebulised distilled water, and metabisulphite. It is not known whether this protective effect is a result of an action on the epithelial cell, inflammatory cells, nerve endings, or smooth muscle. Workers in Nottingham (Knox and Ajao, Thorax 1990;45:856-9) studied both bovine and human airway smooth muscle in vitro. They found that frusemide did not inhibit the smooth muscle contraction induced by histamine, potassium chloride, or hyperosmolar saline and concluded that the effect of frusemide is unlikely to be due to a direct action on airway smooth muscle.

To the best of my knowledge there are as yet no reports of the therapeutic use of inhaled frusemide in asthma. The treatment of asthma is one of the great therapeutic advances of the last 25 years but new work appears constantly, ${ }^{1-4}$ and the near future promises to be equally rewarding.

1 Twentyman OP, Finnerty JP, Harris A, Palmer J, Holgate ST. Protection against allergen-induced asthma by salmeterol. Lancet 1990;336:1338-42.

2 Sears MR, Taylor DR, Print CG, et al. Regular inhaled beta-agonist treatment in bronchial asthma. Lancet 1990;336:1391-6.

3 Wong CS, Pavord ID, Williams J, Britton JR, Tattersfield AE. Bronchodilator, cardiovascular, and hypokalaemic effects of fenoterol, salbutamol, and terbutaline cardiovascular, and hypokalaemic effect

4 Anonymous. $\beta_{2}$ agonists in asthma: relief, prevention, morbidity. Lancet 1990;336: 1411-2. 